\title{
Over-education Issues in Graduated Education of Physical Education in China's Universities
}

\author{
Ruilei Dai \\ Department of Physical Education, Jining College, Qufu, Shandong, 273155, China
}

\begin{abstract}
Under the background of modern commercialized education, the Over-education phenomenon has become widespread. The purpose of this study is to investigate the over-education status in the major of physical education and training of postgraduates in some China's universities. Methods: the study of literature and network information was applied on present situation research of physical education and training of postgraduates. Meanwhile, the questionnaires was used on some master and doctoral graduates' work status quo. Results: some institutions of Physical Education and Training refer to too much professional research direction and professional boundaries are not clear, it made students difficult to apply their knowledge to achieve. Conclusion: The phenomenon of over-education and lack of education in some of China's universities coexist in education above the Bachelor of Physical Education and Training.

Index Terms - over-education, physical education, graduate students, insufficient education
\end{abstract}

\section{Introduction}

Over-education refers to the phenomenon that people's actual education level is far higher than the level required by their work $^{[1]}$. Over-education phenomenon was proposed by the U.S. human resource management experts, and later was used in the field of economics research. It also became an important issue in education. The reason why the concept of "over-education" is firstly proposed in the field of human resources is that many companys find candidates have qualifications higher than the recruitment requirements, it even makes the HRs difficult to recruit employees with suitable level of education. For the high level of education, the employers have to pay them higher salaries, and they actually don't need such a high educational background in practical work. So high level education is a kind of waste of national education resources, and of students as well. When the phenomenon of "over-education" become a common social phenomenon in the economic field, then it becomes a waste, so this phenomenon also caused concern in the field of economics. Moreover, over-education may result in inadequate education in some aspects that students really need. Therefore, it should be paying more attention by modern educators and researchers.

The issue of over-education in China focus many researchers' attention, many investigations were published in variety academic journals in the past decade. Search in CNKI (a most popular online academic database ) with "overeducation" keywords, more than 350 research articles can be found in the literature database. these articles elaborate overeducation and its root causes. There are 45 research papers refering to post secondary education. Visible over education has caused widespread concern of our education scholars. Higher physical education, as an integral part of China's higher education system, also will be subject to the impact of education policies and ideas, therefore, the over-educated also exists in physical education in universities. The purpose of this study is to study the university program of Physical Education and Training from the perspective of "over-education" so as to provide a reference for the professional education reform.

\section{Research Methods}

\section{A. Literature Study}

Find out the universities' name that has doctoral and/or master degree progams by the 2011's Ministry of Education index, and explore the universities' website to know of their curriculum and aims of cultivation. research the universities with master's and doctoral degree in physical education eligibility. conduct a statistical analysis of the situation. At the same time, searching and analyzing some Physical Education institutions' Masters and Ph.D. brochures in 2011 via Baidu search engine.

Research on the topics of 2000-2011 Physical Education and Training Master and Doctoral papers through CNKI(national academic database) in order to understand the graduate students' designations engaged in school during the learning and research activities.

\section{$B$. The questionnaire study}

Using the address book of 2010 National Physical Education and Training conference, the address book of Graduate Education Innovation(courses) of the Ministry of Education in 2008, the address book of the 2010 National Physical Education Teaching and training forum, study the 208 participants by doing surveys through e-mails, analyze how effective are they to apply their knowledge in their work. 65 effective responses from Physical Education and Training Masters and 22 effective responses from Physical Education and Training Doctors were sent back. (graduate year of 2005 and non-Physical Education and Training respondents were discarded).

\section{Statistical Analysis}

EXCEL for statistical analysis of the survey results.

\section{Results}

A. Research fields of the master and doctoral papers of Physical Education and Training

By searching the doctoral thesis of Physical Education and 
Training in the past decade through CNKI, 430 papers were found. By retrieving again according to the classification of the disciplines, the following results were obtained: 390 papers involve the "sports" field; 14 papers involve "secondary education"; 9 papers involve "sports market research and information"; 5 papers involve "special medicine"; 4 papers involve "psychology"; 4 papers involve "higher education"; 4 papers involve "tourist"; 2 papers involve "surgery"; 2 papers involve the "endocrine and systemic diseases"; 2 papers involve "educational theory and management; each one of the other ones relates to the field of "Trades and Economics", "Resources Science "," Pre-school Education "," Medical and Health Principles and Policies "," industrial economics". Based on the function of the classification of the database itself, the category of "Sports" is not very clear, however, there are 390 papers that relate to this field. So we did a specific analysis of this part of the thesis topics, found that there are still a large part of thesis topics that are not involved in the areas of physical education or sports training, such as: "social values research on Beijing Olympic Games ", "contemporary Chinese martial arts and social influence", "Modern Western sports science history", "regional leisure sports industry development", "China's sports information resource allocation", "risk management mechanism of hosting major sports events " "commercial health club marketing experience research" and so on. In other words, in the "Sports" category, there are still many topics outside of the Physical Education and Training. Due to the vast amount of topics and the searching function of the software itself, we can not find specific statistics, but by looking at the contents of these topics, Sports Education and Training seems to be a hodgepodge. Every topic is suitable for the professional name, but by looking from another perspective, what kind of students does Physical Education and Training professionals expect to get in the end? What is the borderline of the program? What kinds of work will students do after graduating from this program? Dissertation topics selected by the institute did not seem to answer these questions very well.

Using the same method, search for master thesis of Physical Education and Training program, due to the large number of students with a master degree in Physical Education and Training each year in China, the study only selected the papers in the network during 2010-2011. 3089 papers were found, involving such areas as classified by subject: papers involving the field of "Sports": 2821; secondary education: 168; "primary education": 30; Higher Education: 25; "specialty medicine": 22;" travel ": 13;" pre-school ": 11; computer software and computer applications: 9; while the rest involve" military "," pediatrics "," market research information "," Administrative Law and local Law "," psychiatry "," service economy "," Music and Dance "," News and Media "," Chinese medicine, "and so the subject areas. In the 2821 papers that involve "Sports" category, also a large part of topics are related to economic, cultural, artistic, which are outside the scope of the Physical Education and Training, Doctoral level topics tend to have a greater dispersion compared to the master topics. For example, there are topics out there like: "Collegiate Athletic propensity to consume", "The operational status of the tennis clubs," Skiers" biomechanics analysis "," Rural Fitness Project Policy Research" and so on. In fact, these topics are exceeding the scope of Physical Education and Training. It seems that Physical Education and Training Master's level is a greater hodgepodge and its research directions are overly broad and unclear. This would definitely affect the employment destinations of graduates, and also affect the directions of the running of the Physical Education and Training as a whole.

\section{B. Substantive Analysis on Over-education of Physical Education and Training}

The Chinese education system, compared with Western countries, starts over educating students from kindergarten ${ }^{[2]}$. Many kindergartens use primary school's curricula, and there are always homework after school because parents and early childhood educators is regarded kindergarten education as the starting line of the future competition. This sense of competition extended to elementary, middle and high school naturally. "Over-education" from kindergarten to high school is in fact to teach the knowledge in latter stages in advance to students. Over education in university is essentially different from over-education in previous stages, the university stage is the final stage of completion of education, professional knowledge and skills of students engaged in the professional work involved is the need to teach students in university education, as society developed refinement and specialization of university education is a "Special Education", the only way to meet the social demand for labor ${ }^{[3]}$. MA, PhD education should be even more explicit, and the directions of their professional curricula should be more in-depth and methodic.

The results of this study suggest that the cultivation objective of graduate Physical Edication programs in the universities need to be more explicit and methodic, what the students learning and research should be closely linked with their work in their future. Especially the doctoral graduates should be trained with more definitely objective and direction, but the results of this study show that the doctoral degree candidates have more all-encompassing research topics. This result may be due to two reasons: Firstly, the point of view from a professional name, Physical Education and Training is the major name of a very rich in content, which includes the direction of sports pedagogy and sports training, while the Physical Education also involves the concept of broad education and narrow education meaning. In this case, the major has the inherent complexity; Secondly, doctoral tutor or advicer became a status symbol, and they enjoy privileges, so many people want to be a doctoral tutor no matter what their position is in the universities, such as pricipal, administrator even a secretary of a facuty or an university ${ }^{[4]}$. It is clear that those tutors don't have their research experience in certain direction, it result into hodgepodge of current graduate education. Meanwhile, some schools want to enhance their reputation by applying eligibility of doctoral degree programs, 
they don't care of their research level or educational results, but of doctor degree itself. Some scholars was invited to be other schools doctoral students' tutor, and they don't really instruct students, they just contribute their scholar title to the school. Masters-level graduate education does not seem to exist to this problem, but the graduate students in research direction and thesis topics lack of a clear positioning either, the programs name and students learned and researched are not coincident as well, at the same time, some graduates engaged in work difference with their learned and researched after they graduate. In fact, the program aims of Physical Education and Training should focus on how to affect the peoples' body, mind and healthy development through exercise; on how to make students master motor skills, to cultivate the students of good character and emotional health through sport activities. While the practice graduate education deviated from the main direction beneath the connotation of the Physical Education and Training. Such as a master's degree students choose the topics of "management status of China's large-scale sporting events", he learned in this direction don't support him to be a instractor of exercise and fitness, or a physical education teacher either. That why today's Physical Education teacher with less than his knowledge of painstaking research, he lacks sufficient understanding and knowledge of
Physical Education, from this perspective, the master's level education for them is insufficient education.

\section{Conclusion}

A. In some higher institutions, the Physical Education and Training programs of Master or doctoral degree has some problems in their cultivation aims, reaserch direction, students' thesis topics coverage too large range, the profession has become a hodgepodge of sports academic areas, dilute the professional name coverage should be the field of the scope and impact of the disciplines of healthy, and sustainable development.

B. Over-education of physical education and training of graduate programs also result into insufficient education of this field. The situation actually is over education and insufficient education co-exist in the programs of Physical Education and Training in some universities.

\section{Reference}

[1] M. Mendes de Oliveira. The role of human capital and technological change in overeducation. Economics of Education Review, 2000,19(2): 199-206

[2] CY Hung, Overeducation and undereducation in Taiwan. Journal of Asian Economics, 2008,19(2): 125-137

[3] http://yz.chsi.com.cn

[4] Gong Mingjun, Thoughts of the Master Degree Education System of Physical Education. Sports Culture Guide. 2011,09 